\title{
The design of an appropriate geothermal energy system
}

\author{
H. Kumashiro ${ }^{1}$, V. Kharisma ${ }^{1,2}$, C. Pamatang Morgana Sianipar ${ }^{1,2}$, \\ K. Koido ${ }^{3}$, R. Takahashi ${ }^{4} \&$ K. Dowaki ${ }^{3}$ \\ ${ }^{1}$ Department of Industrial Administration, \\ Graduate School of Science and Technology, \\ Tokyo University of Science, Japan \\ ${ }^{2}$ School of Business and Management, Institut Teknologi Bandung, \\ Indonesia \\ ${ }^{3}$ Department of Industrial Administration, \\ Faculty of Science and Technology, Tokyo University of Science, Japan \\ ${ }^{4}$ Toshiba Corporation, Japan
}

\begin{abstract}
In this study, we propose an appropriate geothermal energy system. If the plant owner would like to operate this system sustainably, an awareness survey on the plant construction and/or operation among the end-users should be conducted at an early stage. A questionnaire is carried out for the purpose of understanding their consciousness. That is, we investigated the relationship between household monthly income and willingness to pay (WTP) for blackout. As result of our questionnaire, it was shown that many Indonesians do not prefer to disturb their own relaxation times. On the other hand, they understand a crisis of global warming, too. This means that they are likely to have a positive image of the idea of a geothermal plant. This is because our questionnaire revealed that almost all respondents have an eco-friendliness attitude.

We obtained the following concrete suggestions: people have a willingness to pay $933.7[$ [DR $/ \mathrm{kWh}]$ to avoid a blackout for two hours, which has a correlation with their monthly household income. That is, based on our results, we would be able to associate the area in which the residents have high household income with the appropriate promotion area. Also, Indonesia's focus is on renewable energy resources and a steady supply of electricity. It may not be suitable to use geothermal energy for electricity in the household sector.
\end{abstract}


Based on our survey, we propose that geothermal energy is utilized for operating an absorption refrigerator in Kamojang to preserve the agricultural products which are produced in Garut and for Jakarta.

Keywords: geothermal energy, appropriate, Indonesia, willingness to pay, conjoint analysis.

\section{Introduction}

In recent years, Indonesia has achieved an average annual economic growth of around $6 \%$ supported by domestic demand. That is why there are many blackouts in Indonesia. In order to sustain this growth, a sustainable strategy is indispensable [1]. On the other hand, annual $\mathrm{CO}_{2}$ emission from 2005 to 2030 will increase due to fossil fuel electric power generation from the amount of 110 to $810 \mathrm{Mt}-\mathrm{CO}_{2} \mathrm{e} /$ year, which corresponds with the increase from 124 to $970 \mathrm{TWh}$ [2]. They have established the requirement of reducing the amount of $\mathrm{CO}_{2}$ emissions by $26 \%$ from 2005 levels, by the year 2020 [2]. Therefore the country's government has formulated a large-scale power generation plan known as the Crash Program, and the second Crash Program, announced in January 2010, stated that around 10,000 MW of new power supply is to be developed by 2014. The second Crash Program puts the emphasis on developing renewable energy, such as geothermal power generation because the $\mathrm{CO}_{2}$ emission of geothermal power plant is about one-fiftieth of that produced by an oil thermal power plant [2]. The goal is for geothermal power generation to produce $9500 \mathrm{MW}$ [1].

However, there are some problems with resident's concern which the company and/or government failed to promote because of end users opinion. For instance, in Bali, they failed to promote it because people who live there wanted to protect the forest reserves and mountains as a holy place for them [3]. They failed to construct geothermal power plants in Indonesia because local people want to protect forest reserve areas [3] and in California because local people want to keep their area as a resort place [3]. Thus, we must understand the end users in order to propose a geothermal system which is acceptable for end users.

In this study, we propose an appropriate geothermal energy utilization-system based on the end users opinion via a questionnaire.

\section{Research overview}

\subsection{Research design}

Figure 1 shows the research flow. In this study, we regard preliminary research and the main questionnaire as an understanding of the end users opinions (step 1), then we determine how to use geothermal energy and determine stakeholder's criteria for appropriateness (step 2), then we design an appropriate system (step 3), and finally, check whether the proposed system is appropriate as a measure (step 4). In this study, as the first step, we must conduct a questionnaire to understand the end users' opinion. There is some research about the use of an attitude survey towards electricity in Japan [4] and electricity preferences in 
America [5]. However, there is a difference of opinion amongst countries concerning electricity [6]. Thus, we conducted a questionnaire to understand how to and where to use geothermal energy. Based on end users' opinion, we will propose an appropriate system for the promotion area. Then we will carry out an interview for the end users and decision makers as to whether or not it is acceptable.

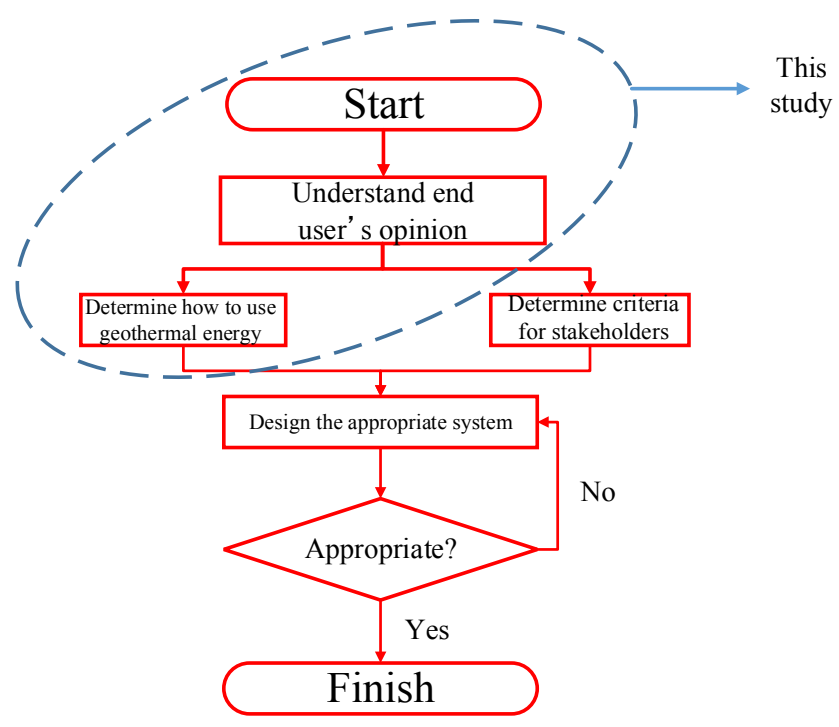

Figure 1: Research design.

\subsection{Survey overview}

In this paper, a questionnaire/survey was conducted to understand Indonesian's opinion for determining which characteristics are the most suitable for geothermal energy and its use. Table 1 shows the survey overview. We utilized the case of a household because we wanted to know the general Indonesian's opinion. Also, we distributed it for all Indonesians because the purpose of this questionnaire is to determine the promotion area for geothermal energy.

Table 1: Questionnaire overview.

\begin{tabular}{|c|c|}
\hline Term & 20 June, 2014-7 July, 2014 \\
\hline Respondent & Website \\
\hline Distribution & All Indonesia \\
\hline Area & 1. Respondent's profile \\
Contents & $\begin{array}{c}\text { 2. Attitude survey toward global warming and geothermal energy } \\
\text { 3. Willingness to pay to avoid a blackout } \\
\end{array}$ \\
4. Electricity preference
\end{tabular}




\subsubsection{Respondent's profile}

We asked the respondents about age, educational background and monthly household income because it tends to bias age by using internet survey [7] and there is a relationship between monthly household income and educational background [8].

\subsubsection{Attitude survey}

In this study, the content of our questionnaire about attitudes is as follows; (1) attitude survey toward blackout; (2) attitude survey toward global warming; and (3) attitude survey toward geothermal power plant. On the content of (1), the following three items are categorized; (a) frequency and duration of blackout [9], and (b) the opinion about blackout. Secondly, on the items of (2), the image of global warming and the sense of danger created by global warming was explored. Lastly, on the items of (3), we enquired about the image of a geothermal power plant.

\subsubsection{Willingness to pay to avoid a blackout}

We must understand the blackout costs for Indonesian people because it is a clear way to understand their attitudes towards a blackout. There are, in principle, three different approaches that can be used to measure the cost of a blackout to households [10]. The first approach involves directly asking their costs for various types of blackout. The second is to study the actual behavior of households in terms of investments aimed at mitigating blackout. The third is to either directly or indirectly ask the households about their WTP to avoid a blackout by stating their preference. In this paper, we asked households their WTP to avoid blackout because this approach considers all welfare effects by including nonmarket effects (e.g. watching TV, cooking and so on) [10].

In this study, we adopted an alternative contingent valuation methodology because this methodology has a high rate of precision. Furthermore, based on previous surveys, to analyze the effect of WTP by changing the duration time of a blackout, we set the two cases as follows; (1) blackout duration is 2 hours (case 1) and (2) blackout duration is 5 hours (case 2).

\subsubsection{Electricity preference}

In this study, we executed a questionnaire on the consumer's electricity preference to understand what kinds of attributes Indonesians focus on. The conjoint analysis is a research technique by which the trade-off relationship between providers would be identified. Also, through the analysis, we can estimate the WTP of attribution. There are three kinds of conjoint analysis methodologies; full profile rating conjoint analysis, pairwise rating conjoint analysis and choice based conjoint analysis [11]. Table 2 shows the attribution data of a preference survey for electricity. Based on the previous survey, we adopted energy resource, cost, environment, steady and safety as attributes [12]. In this study, I adopted green technology as an attribution of the environment because Indonesia is promoting the green economy [13]. 
Table 2: Attribution data of preference survey of electricity.

\begin{tabular}{|c|c|c|c|c|}
\hline Attribution & \multicolumn{3}{|c|}{ Level } \\
\hline Price & $1194.5[\mathrm{IDR} / \mathrm{kWh}]$ & $792.0[\mathrm{IDR} / \mathrm{kWh}]$ & $383.7[\mathrm{IDR} / \mathrm{kWh}]$ \\
\hline Environment & Green technology & $\begin{array}{c}\text { Non-green } \\
\text { technology }\end{array}$ & & 2 \\
\hline $\begin{array}{c}\text { Blackout } \\
\text { frequency }\end{array}$ & $<1$ & 1 & $2<$ \\
\hline Safety & No effect & Shelter & $\begin{array}{c}\text { Health damage, } \\
\text { but no one will die }\end{array}$ & $\begin{array}{c}\text { There is a } \\
\text { possibility } \\
\text { of death }\end{array}$ \\
\hline Resource & Renewable energy & $\begin{array}{c}\text { Non-renewable } \\
\text { energy }\end{array}$ & \\
\hline
\end{tabular}

\section{Results and discussion}

\subsection{Respondents profile}

The respondent's profile is shown in Figure 2. The ratio of less than 29 years is $87 \%$. However, according to the previous research, a ratio of less than 34 years is $62 \%$ [14]. That's why there are more young respondents than general. Next, concerning monthly income, a ratio of more than 4.8 million IDR is about $50 \%$. However, according to previous research, about $50 \%$ of Indonesians are less than 4.8 million IDR and the number of middle-class is between 4.8 million IDR and 14.5 million IDR [15]. Thus about $50 \%$ of respondents are of a high-income class or middle-income class. Lastly, regarding educational backgrounds, about $56 \%$ of respondents graduated from university or school.

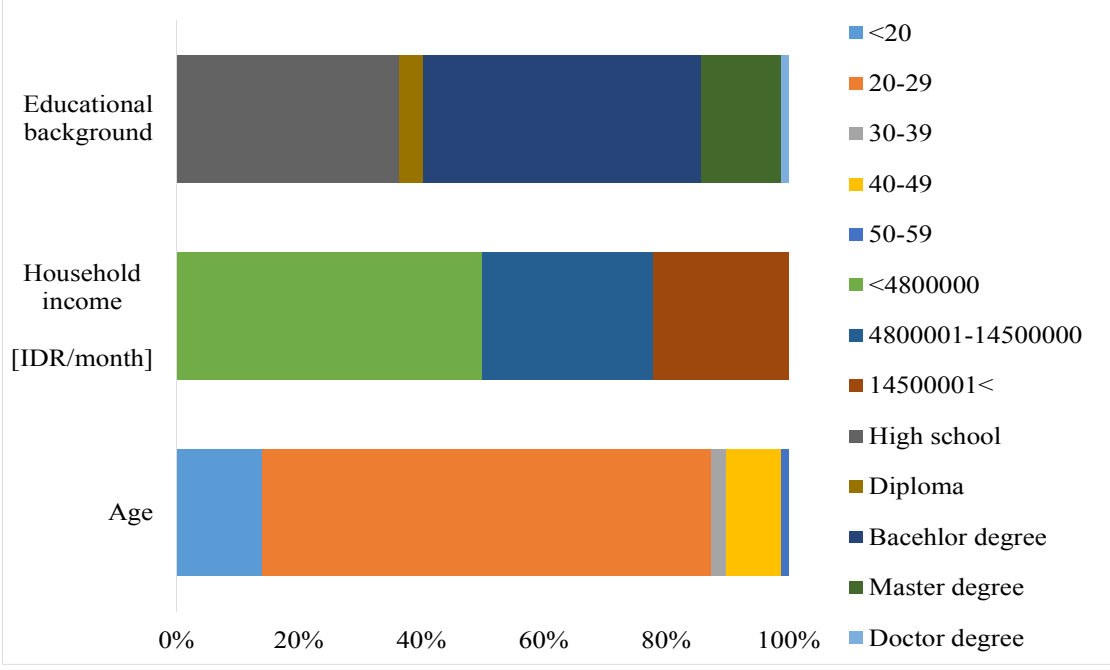

Figure 2: Respondent's profile. 


\subsection{Attitude survey}

\subsubsection{Blackout}

As a result of our questionnaire, about $85 \%$ of respondents answered that a blackout occurs less than twice per month and about $83 \%$ of respondents answered that a blackout lasts for less than 2 hours.

We also asked respondents who were most troubled about the occurrence of a blackout, Figure 3 shows the results. Based on these results, we found that Indonesians are reluctant to be disturbed during their own relaxation time.

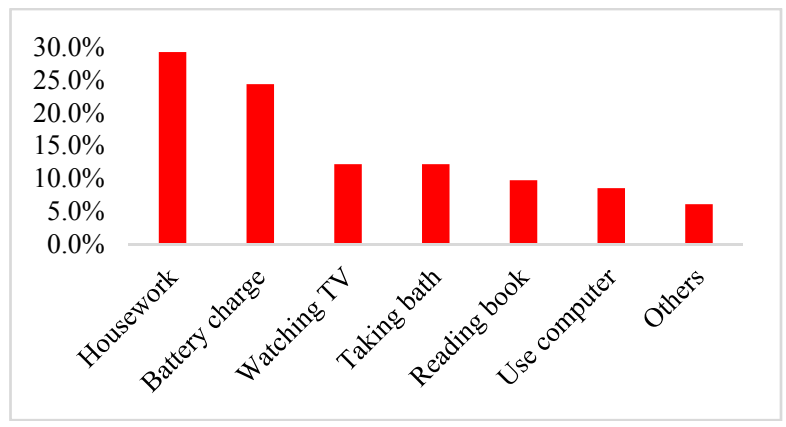

Figure 3: Most troubled by blackout.

\subsubsection{Global warming and geothermal power plant}

We asked respondents about the crisis of global warming. About $92 \%$ of respondents answer that they believe in the crisis of global warming.

We also asked about the image of geothermal energy and Figure 4 shows the results. We found that almost all surveyed people regard geothermal energy as a renewable energy, eco-friendly and a new option. Based on the results of the attitudinal survey toward global warming and geothermal power plants, we found that Indonesians have a good image of geothermal energy.

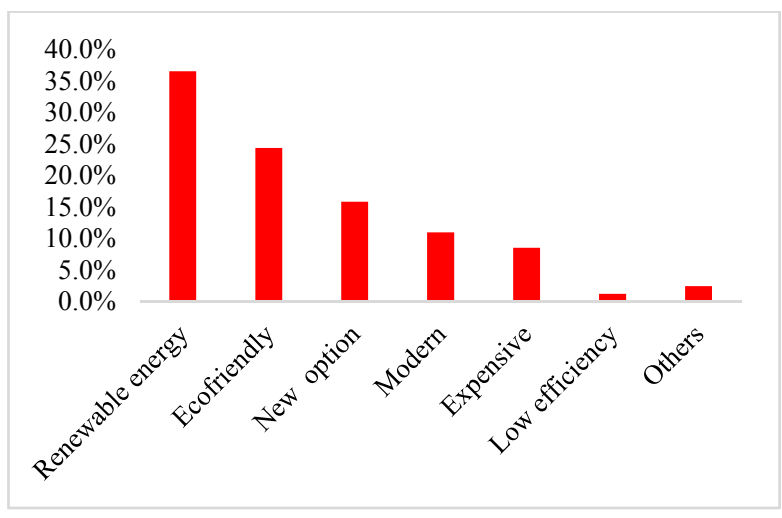

Figure 4: The image of geothermal energy. 


\subsection{Willingness to pay for blackout}

Figure 5 shows the results of the WTP survey. As a result, we discovered that the Indonesian has a WTP to avoid a blackout more than the current electricity price. Also, we found out that high- and middle-class people have a WTP to avoid it more than low-class people do. Based on these results, we found out that the higher the income, the more people tend to hesitate to experience a blackout because they have some home appliances which they need for welfare [16]. That's why we should promote electricity for the area which has more high- and middle-class people in, rather than the other areas, from the view point of appropriateness. Furthermore, Indonesians tend to hesitate over the notion of a long duration of blackout - the WTP for a blackout which remains for 5 hours is higher than which remains for only 2 hours.

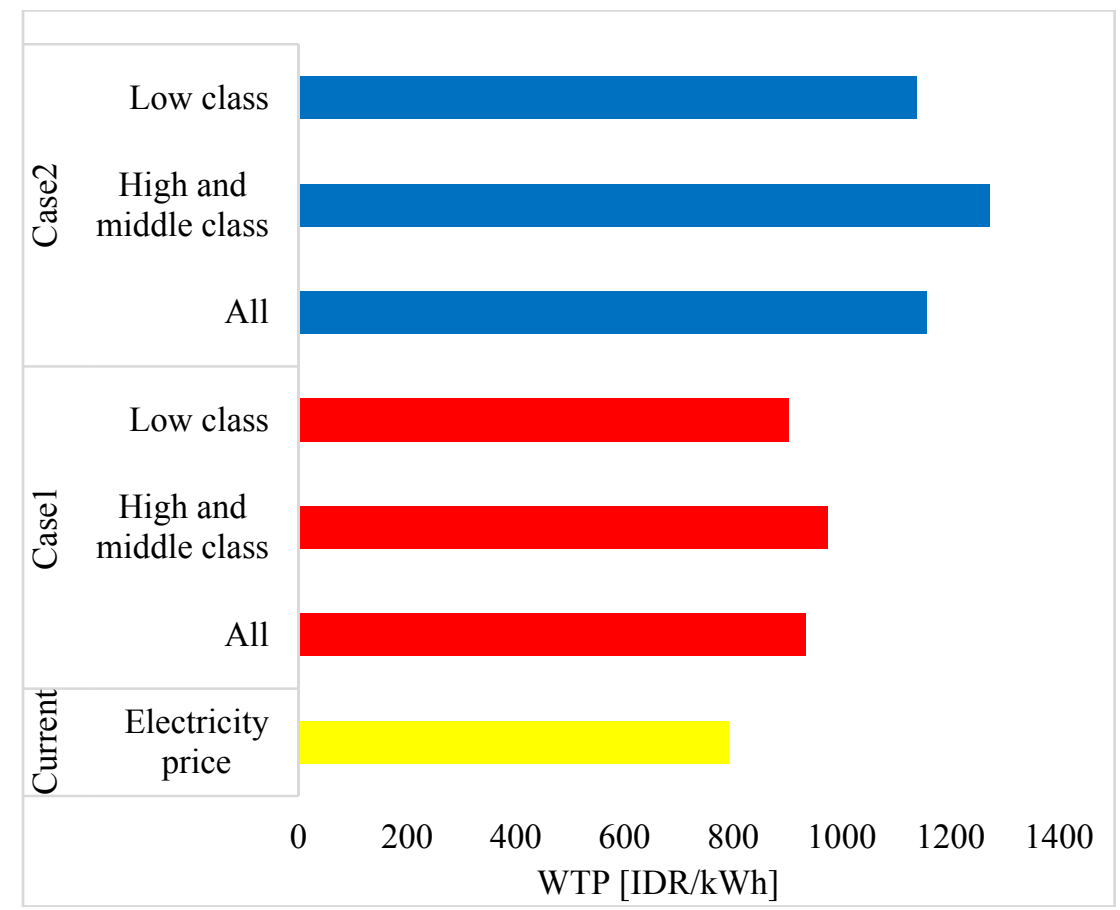

Figure 5: The result of WTP.

\subsection{Electricity preference}

As a result of our survey, the coefficients for each element with the following statistical indexes such $\mathrm{T}$-value and $\mathrm{P}$ value are shown in Table 3. According to the survey, the WTP would not be affected by the environment and the safety of electricity. Thus, we ignored the influence of environmental factors and safety. 
However, based on the test results, we found that the Indonesian focuses on electricity prices, and steady energy resources.

Table 3: Results of preference intensity.

\begin{tabular}{|c|c|c|c|c|}
\hline & Coefficient & $\mathrm{t}$ value & $\mathrm{p}$ value & Test \\
\hline Cost & 0.0016 & 6.068 & 0.000 & $* * *$ \\
\hline Environment & -0.0986 & -0.739 & 0.460 & \\
\hline Steady & -0.2417 & -3.552 & 0.000 & $* * *$ \\
\hline Safety & -0.0180 & -0.158 & 0.875 & \\
\hline Resource & -0.3676 & -5.433 & 0.000 & $* * *$ \\
\hline
\end{tabular}

(Note: *** means $1 \%$ significance.)

Furthermore, we assume that the added value in the real transaction would be 1/3.05 times of the measured WTP [17]. Based on this, the marginal WTP divided by 3.05 is equal to the measured WTP. The result of marginal WTP about a reliably steady source and resource is 48.6 [IDR/kWh] and $74.0[\mathrm{IDR} / \mathrm{kWh}]$, respectively. As a result of the WTP survey, we found out that people focus on energy resources and renewable energy.

\section{Proposal of geothermal energy system}

Based on our questionnaire, we found out that an Indonesian person who belongs to middle- or high-class hesitates at the occurrence of a blackout more than lowerclass person. That's why the area in which there are many people who get a higher salary should be used as a promotional area for geothermal energy utilization and people have a WTP for renewable energy. This means that geothermal energy is a promising energy. As a result, in this study, we regard Jakarta as a potential promotional location for geothermal energy utilization because there are many places that have geothermal resources in West Java [18] and there are more middle- and high-class people than in the other areas [19]. However, as a result of conjoint analysis, people also focus on steady electricity; people dislike the occurrence of a blackout. The capacity factor of geothermal energy is higher than that of wind power; the wind power and tidal [20] equipment of geothermal power plant has been updated [21], but engineers need to close geothermal power plants for maintenance because endogenous fluid includes hydrogen sulfide and it causes erosion of turbine blades [22]. That's why if geothermal energy should to be utilized for electricity, then the maintenance of the output is necessary.

However, geothermal energy can not only be utilized for electricity but also for direct-use [23]. There are some geothermal energy utilizations such as drying and cooling purposes [23]. This means that it has a possibility to use it for heating and cooling. Hence, in this study, we suppose that geothermal energy is utilized for operating an absorption refrigerator as a heat resource and an auxiliary power to preserve agricultural products because Indonesia's population is growing rapidly, which is leading to an increased consumption of horticultural products 
[24] and cold storage systems play an important role in maximizing the shelf-life of products [25]. In this paper, we suppose that Garut is a promising place as a farming area because there are some geothermal resources near Garut (e.g. Kamojang geothermal power plant and Patuha geothermal power plant) and there are agricultural products cultivated, such as tomatoes [26], strawberries [27] and so on. Also, as a result of my research, we set Jakarta as a retail location. Lastly, we set Kamojang as a geothermal resource location because it is near to Garut and we can get the geothermal steam and potential data [28].

\section{Conclusion}

In this study, we proposed the appropriate geothermal energy system based on the questionnaire. We supposed that geothermal energy is utilized for operation in Kamojang geothermal energy. In future work we will choose the target products, calculate the energy required, perform a cost analysis and conduct an environmental analysis.

\section{References}

[1] Marubeni Corporation, Accelerated introduction of geothermal power plants in Indonesia. Japanese government document, pp. 2-8, 2012.

[2] Mitsubishi Corporation, Report on feasibility study of GHG reduction using geothermal power in Indonesia. Japanese Ministry of Economy, Trade and Industry document, pp. 1-50, 2011.

[3] Kondo, H. \& Uchiyama, Y., The spread of geothermal utilization in overseas. A monthly report of The Japan Economic Research Institute, pp. 66-75, 2012.

[4] Kubota, H. \& Baba, K., Public attitude toward mitigation option such as low carbon power technologies and adaptation to climate. Central Research Institute of Electric Power Industry report, pp. 1-41, 2011.

[5] Roe, B., Teisl, M.F., Levy, A. \& Russell, M., US consumer's willingness to pay for green electricity. Energy Policy, 29(11), pp. 917-925, 2001.

[6] Accenture Corporation., Value analysis of new energy consumer. Accenture end user analysis of electricity management in 2011, pp. 3-43, 2011.

[7] Yokohara, H., Present status and problems of web surveys used in marketing. The Institute of Statistical Mathematics, 49(1), pp. 215-222, 2001.

[8] Koguma, S. \& Nanngumo, S. Comparison with the mail survey and Internet research in social research. Research Institute for Advancement of Living Standards Research Note, pp. 20-27, 2011.

[9] Electronic Power System Council of Japan, A survey of power outage cost. Power System Council of Japan research report, pp. 98-135, 2014.

[10] Carlsson, F. \& Martinsson, P. Willingness to pay among Swedish households to avoid power outages. Elforsk report, pp. 3-6, 2009. 
[11] Yukimoto, T., Murakami, K. \& Maruyama, T., Consumer policy and resource management. Economic and Social Research Institute Cabinet Office discussion paper, 271, pp. 1-10, 2011.

[12] Hiwatani, R., Okano, K., Asaoka, Y., Nagano, K., Ogawa, Y., Kato, T., Tobita, K. \& Norimatsu, T., Development of a methodology to evaluate characteristics of energy technology by conjoint analysis. Central Research Institute of Electric Power Industry report, pp. 28-33, 2008.

[13] Gunawan, J. \& Fraser, K., Developing 'green' labour in Indonesia: What is the current state of play? Labour and Management in Development Journal, 14, pp. 1-23, 2013.

[14] The World Bank:

http://databank.worldbank.org/Data/Views/VariableSelection/SelectVariab les.aspx? source $=$ Health $\% 20$ Nutrition $\% 20$ and $\% 20$ Population $\% 20$ Statistics :\%20Population $\% 20$ estimates $\% 20$ and $\% 20$ projections

[15] Cabinet Office, http://www5.cao.go.jp/j-j/sekai_chouryuu/sa11-02/s2_11 2_3/s2_11_2_3_3.html

[16] The Boston Consulting, Indonesia's rising middle-class and affluent consumers: Asia's next big opportunity. The Boston Consulting Report, pp. 1-13, 2013.

[17] List, J.A. \& Garret, C.A., What experimental protocol influence disparities between actual and hypothetical values? Environmental and Resource Economics, 20(3), pp. 241-254, 2001.

[18] Munandar, A. \& Widodo, S., Geothermal resources development in Indonesia. Proc. of the 10 ${ }^{\text {th }}$ Asian Geothermal Symposium, pp. 1-11, 2013.

[19] Taniguchi. K., Lowest wage in 2014. Okayama prefecture Indonesia business support desk report, 28.

[20] Fridleifsson, I.B., Status of geothermal energy amongst the world's energy sources. Geothermics, 32(4-6), pp. 379-388, 2003.

[21] Takei, K., Geothermal turbine technologies contributing to spread of renewable energy. Toshiba review, 63(9), pp. 27-30.

[22] Engineering and Consulting Firms Association Japan. \& Tohoku Electric Power Corporation, Preventions and solutions for the scale problem at the geothermal power plant and CDM study in Indonesia. Japanese government document, pp. 1-11, 2006.

[23] Lund, J.W., Direct utilization of geothermal energy. Energies, 3(8), pp. 1443-1471, 2010.

[24] Maulana, M. \& Sayaka, B., The features of vegetables in Indonesia and the current policy in the framework of agricultural development. Analisis Kebijakan Pertanian, 5(3), pp. 267-284, 2007.

[25] Putri, E.A., Dowaki, K., Yudoko, G. \& Koido, K., Comparison of environment impact between conventional and cold chain management system in paprika distribution process. The Asian Journal of Technology Management, 5(1), pp. 1-12, 2012.

[26] The World Bank, Horticultural producers and supermarket development in Indonesia. The World Bank report, pp. 156, 2007. 
[27] Hanif, Z \& Budiyati, E., Diversity technology strawberry cultivation in different regional production centre. Proc. of Natural Resource Climate and Food Security in Developing Countries, pp. 614-624, 2011.

[28] Agani, M., Rozaq, K. \& Bachurun, Z.I., Construction and operation of Kamojang unit 4, the first commercial geothermal power plant built, owned and operated by PT Pertamina Geothermal Energy. Proc. World Geothermal Congress 2010, pp. 1-7, 2010. 